\title{
A INCLUSÃO DE PESSOAS COM DEFICIÊNCIA E NECESSIDADES EDUCATIVAS ESPECIAIS NO ENSINO REGULAR: VOZES E SIGNIFICADOS
}

\author{
LA INCLUSIÓN DE PERSONAS CON DISCAPACIDAD Y NECESIDADES \\ EDUCATIVAS ESPECIALES EN LA ENSEÑANZA REGULAR: VOCES Y \\ SIGNIFICADOS
}

\section{TO INCLUDE OF PESSOAS COM DEFICIENCY AND EDUCATIONAL NECESSITIES ESPECIAIS NOT ENSINO REGULAR: VOICES AND MEANINGS}

\author{
Elizabeth Regina Streisky de FARIAS ${ }^{1}$ \\ Gilmar de Carvalho CRUZ ${ }^{2}$
}

RESUMO: Este texto objetiva relatar a pesquisa realizada em duas escolas públicas do município de Irati, no estado do Paraná. A pesquisa teve como objetivo analisar a trajetória escolar de alunos com deficiência e os resultados de aprendizagem deles. A pesquisa foi realizada em três etapas, sendo a primeira a observação do cotidiano escolar, nos vários espaços e tempos que compõem a escola. Já a segunda etapa, consistiu em observações realizadas em sala de aula. A terceira etapa contemplou as entrevistas semiestruturadas com os professores que aceitaram participar da pesquisa, na busca da identificação das concepções dos docentes sobre a inclusão dos alunos no ensino comum. A fundamentação desta pesquisa partiu da abordagem histórico-cultura, que tem como autores de referência: Vygotsky (1991), Leontiev (1978). Também foram consultados autores que tratam da aprendizagem de alunos com deficiência, como Stainbach e Stainbach (1992). Utilizou-se também de autores que tratam do cotidiano escolar, como Heller (1970, 1987). A análise dos resultados indicou que, apesar do acesso à escola esteja garantido, por meio da legislação vigente, o cotidiano da escola não sofreu significativa mudança, o que não contribuiu com o sucesso de aprendizagem dos alunos. Porém, compreende-se que a aprendizagem dos alunos com deficiência é possível e ações interventoras de professores podem contribuir de forma significativa no aprendizado dos alunos com deficiência.

PALAVRAS-CHAVE: Inclusão. Escolarização de pessoas com deficiência. Cotidiano escolar.

RESUMEN: Este texto objetiva relatar una investigación realizada en dos escuelas públicas del municipio de Irati, en el estado de Paraná. La investigación tuvo como objetivo analizar la trayectoria escolar de alumnos con discapacidad y los resultados de aprendizaje de ellos. La investigación fue realizada en tres etapas, siendo la primera la observación del cotidiano

\footnotetext{
${ }^{1}$ Universidade Estadual do Paraná (UNESPAR) - Paranaguá - PR - Brasil. Professora no Departamento de Educação, Curso de Pedagogia, na Universidade Estadual do Paraná - UNESPAR - Campus Paranaguá. ORCID: <https://orcid.org/0000-0002-3261-7756>.E-mail: bety.farias@bol.com.br

${ }^{2}$ Universidade Estadual do Centro Oeste (UNICENTRO), Ponta Grossa - PR - Brasil. Professor associado da Universidade Estadual do Centro-Oeste (UNICENTRO) e professor permanente do Programa de Pós-Graduação em Educação da Universidade Estadual de Ponta Grossa (UEPG). ORCID: <https://orcid.org/0000-0001-66260727>.E-mail: gilmailcruz@gmail.com
} 
escolar, en los varios espacios y tiempos que componen la escuela. La segunda etapa, consistió en observaciones realizadas en el aula. La tercera etapa contempló las entrevistas semiestructuradas con los profesores que aceptaron participar de la investigación, en la búsqueda de la identificación de las concepciones de los docentes sobre la inclusión de los alumnos en la enseñanza común. La fundamentación de esta investigación partió del abordaje histórico-cultural, que tiene como autores de referencia: Vygotsky (1991), Leontiev (1978). También se consultó a los autores que se ocupan del aprendizaje de alumnos con discapacidad, como Stainbach y Stainbach (1992). Se utilizó también de autores que tratan del cotidiano escolar, como Heller (1970, 1987). El análisis de los resultados indicó que, a pesar del acceso a la escuela está garantizado, por medio de la legislación vigente, el cotidiano de la escuela no sufrió significativo cambio, lo que no contribuyó con el éxito de aprendizaje de los alumnos. Sin embargo, se comprende que el aprendizaje de los alumnos con discapacidad es posible y acciones interventoras de profesores pueden contribuir de forma significativa en el aprendizaje de los alumnos con discapacidad.

PALABRAS CLAVE: Inclusión. Escolarización de personas con discapacidad. Cotidiano escolar

ABSTRACT: This text aims to report a survey conducted in two public schools in the municipality of Irati, in the state of Paraná. The research aimed to analyze the school trajectory of students with disabilities and their learning results. The research was carried out in three stages, the first being the observation of school everyday, in the various spaces and times that make up the school. The second stage consisted of observations made in the classroom. The third stage included semi-structured interviews with teachers who agreed to participate in the research, in the search for the identification of teachers' conceptions about the inclusion of students in common teaching. The foundation of this research was based on the historicalcultural approach, which has as reference authors: Vygotsky (1991), Leontiev (1978). We also consulted authors that deal with the learning of students with disabilities, such as Stainbach and Stainbach (1992). It was also used authors who deal with school every day, such as Heller $(1970,1987)$. The analysis of the results indicated that, although access to school is guaranteed, through current legislation, the daily life of the school did not suffer significant change, which did not contribute to the students' learning success. However, it is understood that the learning of students with disabilities is possible and intervening actions of teachers can contribute significantly to the learning of students with disabilities.

KEYWORDS: Inclusion. Schooling of people with disabilities. School daily.

\section{Introdução}

O tema da inclusão, tem sido pauta da sociedade em geral. Porém, discutir a escola e as possibilidades da inclusão, em seu meio é complexo e desafiador. Isto ocorre, porque a escola tem apresentado dificuldades de cumprir sua função social de garantir a aprendizagem de todos os alunos, inclusive dos alunos com deficiência. 
Embora alguns avanços tenham ocorrido, quanto ao acesso dos alunos com deficiência no ensino comum, especialmente orientados por movimentos mundiais pela inclusão, a permanência e a aprendizagem com qualidade, nem sempre é garantida.

A pesquisa foi desencadeada a partir do interesse da pesquisadora pela inclusão, já que a trajetória profissional permitia revelar situações de exclusão no ambiente, que se manifestava por uma prática pedagógica arcaica, baseada em um ensino frontal, bem como no não reconhecimento do papel da família na escola. Nem sempre esta inclusão era clara, mas muitas vezes era velada, mas que se concretizava por meio do abandono pedagógico, da falta de compromisso em relação ao processo ensino e aprendizagem.

Com relação aos suportes oferecidos aos alunos com deficiência, pode-se dizer que muitas vezes eles não são significativos, de modo especial quando se trata da deficiência intelectual, tendo em vista que os suportes necessários envolvem: formação continuada consistente, recursos humanos e financeiros.

As práticas realizadas na escola, na organização dos tempos e espaços, têm se mostrado elitista e excludente, portanto, a exclusão não é apenas sentida por alunos com deficiência, mas por todos os que de alguma forma, não se sentem pertencentes ao contexto escolar.

Nesta perspectiva, a escola reproduz as desigualdades evidenciadas em uma sociedade dividida em classes antagônicas, quando não garante a aprendizagem de todos os seus alunos.

Esta pesquisa, buscou analisar o cotidiano escolar e as praticas que denunciam a inclusão e a exclusão, sendo que a opção metodológica a abordagem etnográfica, que representa um suporte metodológico que contribui na compreensão das práticas sociais. Esta escolha diz respeito.

A fundamentação teórica privilegiou a abordagem histórico-cultural, tendo Vygotsky (1988, 1991) e Leontiev (1978, 2006), como seus principais representantes. Também foram utilizados autores como Heller (1970, 1987), na compreensão do cotidiano escolar e Stainback e Stainback (1992), no estudo sobre a deficiência e a escolarização.

Os objetivos da pesquisa foram analisar a trajetória escolar de alunos com deficiência, do sexto ao nono ano do Ensino Fundamental, bem como o impacto no processo de aprendizagem destes alunos. Também analisar os documentos legais norteadores das escolas que embasam o trabalho do professor; observar o cotidiano na busca de elementos que identifiquem aspectos inclusivos ou excludentes no espaço escolar; identificar as concepções de docentes sobre a inclusão de alunos com deficiência ou com necessidades educativas especiais na escola. 


\section{O Direito de todos à Aprendizagem}

Ao longo da história o segmento populacional constituído por pessoas consideradas diferentes, sofreram importantes transformações. Atualmente, compreendesse que cada pessoa, deve ter acesso à educação, para garantir suas necessidades básicas de aprendizagem.

A perspectiva inclusiva, considerada um novo paradigma educacional, tem como pressuposto a crença de uma escola para todos, com igualdade de oportunidades de aprendizagem. Como politica educacional, a inclusão busca resgatar uma divida com uma população que historicamente, tem ficado à margem da sociedade.

A trajetória da escolarização de pessoas com deficiência, passou por diferentes paradigmas, como: institucionalização, normalização, integração e suporte.

O paradigma da institucionalização, teve suas raízes fundantes na segregação das pessoas com deficiência. Buscava-se afastar estes indivíduos da sociedade, geralmente segregados em instituições especializadas, tendo como justificativa que, fora da sociedade, teriam proteção e cuidados melhores. A promessa deste paradigma era que segregadas as pessoas com deficiência, seriam preparadas para a vida, o que poucas vezes acontecia. Este paradigma perdurou até o fim da década de 1960.

Tendo como principio a normalização, desponta o paradigma de serviços, que considerava o individuo com deficiência, como sujeito de direito à convivência com os demais indivíduos, porém este convívio estava atrelado a modificação do sujeito, que o tornassem com características, que se aproximassem aos demais integrantes da sociedade.

Nesta perspectiva, acreditava-se que os indivíduos só poderiam ser integrados na sociedade, se participassem de serviços de diferentes áreas de atendimento clinico.

Esta oferta de serviços organizava-se em três etapas. A primeira que identificava a condição do individuo e tudo o que deveria ser modificado nele, para torná-lo o mais normal possível, a segunda, a intervenção, que se dava por meio de atendimento formal e sistemático e a terceira, que encaminhava a pessoa com deficiência aos serviços da comunidade (BRASIL, 1994).

O paradigma da integração, tem como pressuposto a transferência da responsabilidade de mudança para a pessoa com deficiência. Esta integração, condicionada à mudança do individuo, teve como resultado uma exclusão automática desse grupo, tendo em vista que os indivíduos sem deficiência, com reais perspectivas de sucesso, sempre foram priorizados pela escola (MANTOAN, 2003). 
Apesar do paradigma da integração, estar longe de realmente incluir, teve como mérito abrir o espaço escolar para as pessoas com deficiência, com abertura de classes especiais. Os alunos com deficiência deveriam adaptar-se à escola, buscando meios de garantir sua permanência na escola (FERNANDES, 2006).

O paradigma de suporte se propõe a inclusão, indicando várias medidas que buscavam incluir os indivíduos com deficiência, que não se restringiam a avaliar e capacitar, mas pautavam-se por atitudes de respeito, dignidade e justiça, na busca da superação da visão do individuo isolado (MANTOAN, 2003).

Nesta perspectiva, os suportes são oferecidos no âmbito social, econômico, físico e instrumental, para assegurar a inclusão. Há muito que ser feito na efetivação desses princípios, considerados que muitos precisam ser superados para que se atinja o proposto.

Embora tenham sido apresentados separadamente, é importante reconhecer que os paradigmas coexistem e estão presentes na prática escolar. Ainda há que se romper com a descrença da escolarização das pessoas com deficiência e caminhar em direção à construção de escolas inclusivas.

Autores como Mantoan (2006) e Figueiredo (2008), defendem a inclusão, de forma ampla, porém com os suportes necessários para a garantia da aprendizagem.

Beyer (2006), analisa que um projeto pedagógico inclusivo, não pode categorizar os indivíduos como com ou sem deficiência. Não há dois grupos de alunos, porém alunos que compõe a comunidade escolar, que tem necessidades variadas.

Glat (2007, p. 24) adverte que "[...] embora as escolas privilegiem um discurso de aceitação à diversidade, na prática não se modificam para dar conta das especificidades de aprendizagem e desenvolvimento de todos os alunos".

Um dos entraves para a consolidação da inclusão, é a falta de suporte, o que envolve investimentos financeiros e pedagógicos, portanto, o desafio das escolas que recebem alunos com deficiência, superando o paradigma de integração, é avançar, promovendo a inclusão, acreditando que o planejamento docente e a organização da escola, levem em consideração a realidade do aluno com deficiência e utilizem metodologias variadas que tenham como pressuposto o respeito à singularidade de cada aluno. 


\section{A Inclusão e a Exclusão: duas faces de uma mesma moeda}

Compreende-se que incluir significa fazer parte de um todo, já excluir é deixar de fora, expulsar. Neste sentido, não são as leis ou ações isoladas que garantirão a inclusão, mas é necessário mudanças de atitudes, concepções, fundamentadas em princípios inclusivos.

Desta forma, programas governamentais e ações ligadas à uma política educacional, podem contribuir para que a inclusão se efetive, mas também podem reafirmar a exclusão existentes na sociedade, ou seja, embora um aluno tenha acesso à escola, pode permanecer excluído da aprendizagem.

É necessário considerar a inclusão como principio educativo, contribuindo na construção de uma escola mais inclusiva, que produzira uma sociedade mais igualitária. Nesta perspectiva, uma escola inclusiva, não beneficia os alunos com deficiência, mas a todos os alunos.

Acredita-se que quando a escola objetiva a diminuição dos entraves à aprendizagem dos alunos com deficiência, contribui também para a aprendizagem de todos os alunos. Assim, a escola deve se tornar um lugar de estimulo, no qual toda a comunidade escolar sinta-se acolhida.

A abordagem histórico-cultural de Vygotsky (1991), contribui na compreensão da educação inclusiva, já que compreende o aspecto cognitivo determinado histórica e culturalmente.

Segundo Freitas (2000), os estudos de Vygotsky, buscam compreender como os fatores sociais modificam a mente, entendendo o homem como ser histórico e social, resultado das relações sociais estabelecidas.

Sendo assim, para Vygotsky (1991), o desenvolvimento humano é resultado de organização mental, que movimenta vários processos, que envolvem o que o individuo consegue realizar sem ajuda e o que ele precisa de mediação, mas que tem potencial para resolver sozinho. Esta mediação, no ambiente escolar, é realizada pelo professor, que reconhece em seu aluno um sujeito aprendente.

Vygotsky (1991), embora reconheça o sujeito biológico, considera as determinações sociais relevantes, já que sua formação inclui social, histórica e culturalmente.

Porém, a escola ainda valoriza o que o indivíduo já sabe, desconsiderando o potencial que ele tem para aprender. A avaliação praticada na escola, considera o nível de aprendizagem que o aluno se encontra, mas não considera as potencialidades do sujeito.

Sobre o ensino de crianças com deficiência, Vygotsky (1991, p. 100), menciona que: 
[...] o sistema de ensino baseado somente no concreto - um sistema que eliminado ensino tudo aquilo que está associado ao pensamento abstrato falha em ajudar as crianças retardadas a superarem suas deficiências inatas, além de reforçar essas deficiências, acostumando as crianças exclusivamente ao pensamento concreto e suprimindo, assim os rudimentos de qualquer pensamento abstrato que essas crianças ainda possam ter. precisamente porque as crianças retardadas, quando deixadas a si mesmas, nunca atingirão formas bem elaboradas de pensamento abstrato, e que a escola deveria fazer todo esforço para empurrá-las nessa direção, para resolver nelas o que esta intrinsecamente faltando no seu próprio desenvolvimento .

Este estudo, se fundamentou no princípio de que toda pessoa pode aprender, embora de formas diferentes, nos aspectos físicos, mentais, sensoriais, neurológicas ou emocionais.

\section{A Pesquisa de Campo}

Nesta pesquisa, optou-se por uma abordagem etnográfica e teve como instrumentos a observação estruturada seletiva, que consiste na observação e descrição dos eventos em função do problema de pesquisa, sendo que o roteiro atendia a quatro eixos: relação do aluno com outras pessoas do cotidiano escolar, relação do aluno com o espaço da escola, relação do aluno com o tempo escolar e relação do aluno com as atividades propostas pelo professor. Estes eixos buscaram identificar as posições dos sujeitos e os significados manifestados por eles. Também foi utilizada a entrevista semiestruturada, que possibilita uma flexibilidade ao pesquisador, a partir dos elementos trazidos pelo entrevistado. Contribui para a pesquisa, já que fornece perspectivas dos participantes, que não ficaram evidentes na observação.

$\mathrm{Na}$ análise documental, privilegiou-se documentos: as orientações enviadas pelo Núcleo Regional de Educação, Secretaria Municipal de Educação e documentos produzidos pela escola, como: o Projeto Político Pedagógico, as pastas individuais dos alunos sujeitos da pesquisa, que tinham relatórios produzidos pelos professores.

Foram selecionados sete alunos para participarem da pesquisa. Os critérios estabelecidos para a seleção dos alunos foram: ter passagem pela escola pesquisada que atende os anos iniciais do Ensino Fundamental, estar matriculado na escola pesquisada que atende a Educação Básica nos anos finais do Ensino Fundamental ou Ensino Médio, ter matrícula na Sala de Recursos Multifuncionais, frequentar regularmente tanto o ensino comum quanto o Atendimento Educacional Especializado na Sala de Recursos Multifuncionais, obter autorização da família para a realização da pesquisa, obter autorização da escola para a realização da pesquisa. 
Nove professores foram selecionados para participar da pesquisa, sendo utilizados os seguintes critérios de seleção: aceitar participar da pesquisa, ser professor na escola pesquisada, ser professor de aluno (s) selecionado (s) para participar da pesquisa.

A pesquisa seguiu a seguinte trajetória:

a) Pesquisa documental, que incluiu o estudo do Projeto Político Pedagógico de cada escola, documentação dos alunos (ficha individual, histórico, dados clínicos, relatórios de professores da sala comum e relatórios de professores da Sala de Recursos Multifuncionais);

b) Observação dos espaços escolares e participação em momentos diversos de atividades escolares;

c) Observação dos alunos selecionados, na Sala de Recursos Multifuncionais;

d) Observação dos alunos selecionados na sala comum;

e) Observação dos alunos selecionados no intervalo das aulas, fora da sala de aula.

A observação dos alunos foi realizada no contexto da sala comum e na Sala de Recursos Multifuncionais, sendo que a análise dos dados coletados do cotidiano escolar, indica que os alunos com deficiência sentem-se mais à vontade nas Salas de Recursos Multifuncionais, o que é demonstrado pela espontaneidade da conversa com colegas, nas perguntas feitas para os professores e no prazer que demonstram ao frequentar a sala, raramente faltando.

Por outro na sala de aula comum, demonstram interesse pelo que é ensinado e persistência ao executar as tarefas propostas.

As Salas de Recursos Multifuncionais, representam um suporte no qual os alunos confiam. Perguntam quando tem dúvida, pedem para realizar as atividades de que gostam, enfim, sentem-se à vontade.

Quanto às salas comuns, não foi observado, previsão de suportes para alunos com deficiência, tampouco alterações metodológicas, reforçando a ideia que a inclusão existente é apenas física, e o sucesso ou fracasso da aprendizagem do aluno com deficiência, é em grande medida determinado pelo trabalho realizado nas SRMs.

A observação do cotidiano escolar, bem como as entrevistas realizadas, aponta para uma concepção e prática, longe de uma inclusão efetiva. Uma questão apontada pelos professores, diz respeito ao despreparo do professor, resultado de uma formação inicial fragmentada e de uma formação continuada distante da realidade. 
Os professores apontam alguns conhecimentos que julgam relevantes para a sua formação. Como: ter conhecimento específico sobre as áreas de deficiência, conhecer teorias de aprendizagem e conhecer a legislação, conhecer e compreender a importância dos pressupostos da educação inclusiva, uso das tecnologias para o ensino. Estes conhecimentos, sugerem, poderiam fazer parte das ementas das disciplinas dos cursos de formação de professores. Porém, sabe-se que os cursos de formação de professores contemplam poucas disciplinas voltadas à inclusão.

Contudo, compreende-se que não só o aumento da carga horárias destas disciplinas poderá garantir a consistência na perspectiva de uma formação inclusiva, mas é importante que a educação especial inclusiva seja um tema transversal que perpasse por outras disciplinas dos cursos de licenciatura (VITALIANO; MANZINI, 2010; FREITAS; MOREIRA, 2011).

Outro entrave apontado pelos professores, para a inclusão, diz respeito ao currículo que é trabalhado superficialmente, não garantindo o avanço na aprendizagem. Ainda quanto ao currículo, os professores apontam que ele não é flexibilizado para o aluno com deficiência, o que impõe uma lógica cartesiana a ele.

A avaliação foi apontada como um dos entraves da escola inclusiva, já que é aplicada da mesma forma para todos os alunos, não considerando a singularidade das pessoas com deficiência.

As avaliações têm, portanto, contribuído para o processo de exclusão, na medida em que não consideram o aluno como sujeito da aprendizagem.

Libâneo (1991, p. 198), aponta que:

a) O equivoco mais comum é usar a avaliação somente para dar notas, classificando o aluno em 'melhor' ou 'pior', dependendo mais do que memorizou do que das aprendizagens significativas que realizou. Ainda é comum o professor ser considerado 'competente', pelo total de alunos reprovados na turma.

b) Outro equivoco é atribuir à avaliação uma função disciplinar, usando os resultados para recompensar ou punir o aluno pelas atitudes demonstradas.

c) $\mathrm{O}$ terceiro equivoco se dá pela realização das chamadas 'profecias pedagógicas'. Muitas vezes o professor confiando no seu 'olho clinico', profetiza desde cedo quais os alunos que têm condições de aprovação ou reprovação, abandonando a avaliação contínua (formativa).

d) O quarto equivoco ocorre quando o professor rejeita medidas quantitativas da aprendizagem, em favor somente dos dados qualitativos ou vice-versa. Considerar, na avaliação, apenas aspectos quantitativos ou somente qualitativos é um erro, deve-se buscar o equilíbrio entre ambos.

Sendo assim, consideram-se relevantes as flexibilizações curriculares, o que podem acontecer por meio de instrumentos diferenciados, com o objetivo de atender os diferentes 
ritmos e estilos de aprendizagem. Importante destacar, que a avaliação, nesta perspectiva, não tem como objetivo de comparar alunos, mas sim identificar os avanços de cada um e as possíveis intervenções que deverão ser realizadas.

Neste sentido, mudar a lógica da exclusão presente em muitas avaliações, representa uma quebra de paradigmas, rompendo com barreiras atitudinais, de aceitação do diferente, rejeitando formas segregacionista de ensino.

A inclusão, compreendida como princípio, tem em sua base, o acesso ao conhecimento dos alunos com deficiência, abrindo-se novas experiências de práticas pedagógicas, flexibilizando o currículo e transformando a lógica da escola.

A pesquisa identificou também que, quando o professor acredita no potencial do aluno, sua prática é influenciada, com vistas ao desenvolvimento do aluno.

Também foi possível identificar que o professor se sente inseguro sobre como trabalhar com os alunos com deficiência, gerando desestabilidade na sua identidade docente, já que desconhecem ou tem dificuldades de utilizar metodologias diversificadas para que todos os alunos aprendam.

É possível assegurar que ações isoladas de professores, bem como o trabalho realizado na Sala de Recursos Multifuncionais, têm contribuído para o avanço na aprendizagem dos alunos, porém, a inclusão ainda não se concretizou do ponto de vista da coletividade. Há ainda várias barreiras a serem rompidas, como: a barreira atitudinal de alguns profissionais da escola, a falta de articulação entre o ensino comum e a Sala de Recursos Multifuncionais. Porém, a crença na possibilidade da aprendizagem dos alunos por parte de alguns professores, nos indicam uma possibilidade real da construção de uma escola inclusiva.

\section{Considerações finais}

Esta pesquisa objetivou analisar o processo inclusivo, por meio da análise documental, da observação do cotidiano escolar e da análise das entrevistas realizadas com a equipe gestora e professores.

A análise da educação como direito e da interpretação da Educação Especial, nos diversos contextos históricos, foram às reflexões iniciais deste trabalho. E contribuíram para a compreensão da lógica com a qual a escola trabalha com os alunos com deficiência.

Com relação ao processo ensino e aprendizagem, a análise realizada nesta pesquisa, identificou que se as práticas pedagógicas estiverem permeadas pelo descrédito que a escola 
tem sobre o aprendizado do aluno com deficiência, o ensinar pode perder o significado. Neste sentido, julga-se natural segrega-lo ou desistir dele.

Destaca-se como ponto central a compreensão de que as pessoas, são sujeitos sociais e com as pessoas com deficiência não é diferente. É preciso lembrar da totalidade do ser, para além de sua deficiência, a pessoa tem preferências, crenças, sonhos e, portanto, um rótulo de sua deficiência não o define.

Ressalta-se que, a organização das escolas pesquisadas, denuncia a exclusão, que é percebida em vários aspectos. No que diz respeito ao espaço físico, esse não possui nenhum elemento que indique um cuidado com os alunos com deficiência: não há rampas para cadeirantes, pista tátil ou materiais específicos para alunos surdos. É possível afirmar que, isto se deve ao fato de o poder público prever as mudanças a partir das necessidades que surgem, muitas vezes atendendo precariamente. Na construção da escola inclusiva, o trabalho antecede a chegada do aluno com deficiência, mas está preparada para todos os alunos que dela podem se beneficiar.

A análise dos dados coletados indicou que, embora o ordenamento legal assegure a matrícula do aluno com deficiência no ensino regular, a escola em seus aspectos organizativos não se alterou, perpetuando a não aprendizagem e o fracasso escolar.

Embora a organização da escola não indique uma intencionalidade de rompimento de práticas em que predominam o ensino frontal e conteudista, alguns professores, desenvolvem práticas inclusivas, garantindo o acesso ao currículo e ao aprendizado de todos os alunos.

Os alunos com deficiência podem aprender, embora com ritmos e estilos diferenciados e o trabalho realizado na Sala de Recursos Multifuncionais, contribui significativamente para que o aprendizado aconteça.

Isto ocorre porque a lógica da Sala de Recursos Multifuncionais difere do ensino comum, já que tem como ponto de partida, as potencialidades dos alunos e não as dificuldades que apresenta. Já na sala comum, prevalece o ensino por meio de uma prática homogeneizadora, com foco nos resultados em forma de notas, segundo este modelo não se prioriza a aprendizagem dos alunos com ritmos diferenciados.

Concorda-se com Michels (2011), quando afirma que dada a complexidade do trabalho com alunos com deficiência na perspectiva inclusiva e a formação nem sempre consistente, $o$ professor da SRMs é um gestor de recursos de aprendizagem, já que são responsáveis, muitas vezes sozinhos, pela aprendizagem dos alunos. 
A pesquisa revelou as contradições e as possibilidades encontradas pelos professores das escolas pesquisadas, para garantir o acesso de todos os alunos, porém, considera-se relevante a ampliação do debate, para as questões pedagógicas, de forma que não só o acesso seja assegurado, mas também a permanência com sucesso de todos os alunos.

Sendo assim, é importante a criação de uma rede de apoio que possibilite as interações sociais e educacionais, promovendo o desenvolvimento. Sem um trabalho coletivo e investimentos necessário, a inclusão não acontecerá efetivamente, mas apenas vai mascarar a exclusão, que é mais perversa que a segregação, já que gera na pessoa com deficiência, o sentimento de incapacidade e de não pertencimento.

\section{REFERÊNCIAS}

BEYER, O. H. Da integração escolar a educação inclusiva: implicações pedagógicas. In: BAPTISTA, C. et al. (Orgs.). Inclusão e escolarização: múltiplas perspectivas. Porto Alegre: Mediação, 2006.

BRASIL. Secretaria de Educação Continuada, Alfabetização, Diversidade e Inclusão. Política Nacional de Educação Especial. Brasília, 1994. Disponível em:

http://portal.mec.gov.br/index.php?option=com_docman\&view=download\&alias=16690politica-nacional-de-educacao-especial-na-perspectiva-da-educacao-inclusiva05122014\&Itemid=30192. Acesso em: 07 ago. 2016.

FERNANDES, S. Fundamentos para Educação Especial. Curitiba: Ed. IBPEX, 2006.

FIGUEIREDO, R. V. (Relatório de pesquisa) Gestão da Aprendizagem na Diversidade. Universidade Federal do Ceará. 2008.

GLAT, R. (Org.) Educação Inclusiva: cultura e cotidiano escolar. Rio de Janeiro: 7 Letras, 2007.

HELLER, A. O cotidiano e a história. 4. ed. São Paulo: Paz e Terra, 1970.

HELLER, A. Sociologia de la vida cotidiana. 2. ed. Barcelona: Península, 1987.

LEONTIEV, A. N. O desenvolvimento do psiquismo. Lisboa: Horizonte Universitário, 1978.

LIBÂNEO, J. C. Didática. São Paulo: Cortez, 1991.

MANTOAN, M. T. E. Inclusão escolar: o que é? Por quê? Como fazer? São Paulo: Moderna, 2003.

MANTOAN, M. T. E.; PRIETO, R. G.; ARANTES, V. A. (Orgs.). Inclusão escolar: pontos e contrapontos. São Paulo: Summus, 2006. 
MICHELS, M. H. O que há de novo na formação do professor da educação especial. Rev. Educ. Espec., Santa Maria, v. 24, n. 40, p. 219-232, maio/ago., 2011. Disponível em: http://www.ufsm.br/revistaeducacaoespecial. Acesso: 24 maio 2016.

STAINBACK, S.; STAINBACK, W. (Orgs.). Curriculum considerations in inclusive classrooms: facilitating learning for all students. Baltimore: Brookes, 1992.

VITALIANO, C. R.; MANZINI, E. J. A formação inicial de professores para inclusão de alunos com necessidades educacionais especiais. In: VITALIANO, C. R. (Org.). Formação de professores para a inclusão de alunos com necessidades educacionais especiais. Londrina: EDUEL, 2010. p. 49-112.

VYGOTSKY, L. S. A formação social da mente. São Paulo: Martins Fontes, 1991.

\section{Como citar este artigo:}

FARIAS, Elizabeth Regina Streisky; CURZ, Gilmar de Carvalho. A inclusão de pessoas com deficiência e necessidades especiais no ensino regular: vozes e significados. Revista IberoAmericana de Estudos em Educação, Araraquara, v. 14, n. 3, p. 1139-1151, jul./set., 2019. eISSN: 1982-5587. DOI: 10.21723/riaee.v14i3.11777

Data de Submissão: $17 / 09 / 2018$

Revisões requeridas: 10/10/2018

Aceite em: 15/02/2019

Publicado em: 10/05/2019 